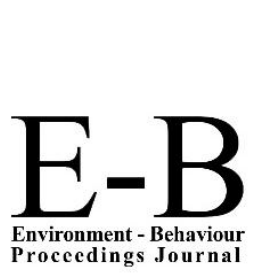

\author{
ASLI QoL 2017 \\ AQoL2017Kuching \\ http:/www.amerabra.org; https:/fspu.uitm.edu.my/cebs \\ $3^{\text {rd }}$ ABRA International Conference on Quality of Life \\ "Quality of Life 3"
}

Riverside Majestic Hotel, Kuching, Malaysia, 14-16 Oct 2017

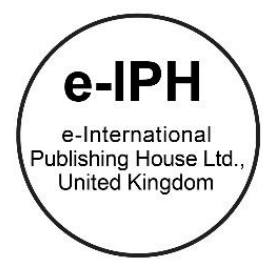

\title{
Design Thinking: Interior Architecture and Interior Design in Thailand
}

\author{
Charlie Maturakarn ${ }^{1 *}$, Chumporn Moorapun ${ }^{2}$ \\ $1 \mathrm{PhD}$ Candidate in Multidisciplinary Design Research Program, Faculty of Architecture, \\ King Mongkut's Institute of Technology Ladkrabang, Bangkok, Thailand \\ 2 Faculty of Architecture, King Mongkut's Institute of Technology Ladkrabang, Bangkok, Thailand \\ charlie.maturakarn@gmail.com \\ Tel:+6685 5051873
}

\begin{abstract}
This research aims to explore the aspects of design thinking of students from two different curricula: Interior Architecture (five years) and Interior Design (four years) to see what different aspects of design thinking of students from each curriculum. The research method is a survey based on quantitative approach. A questionnaire is developed from Perry scheme of intellectual development and Kolb's Experiential Learning Theory (ELT) model. 120 participants were selected from two universities. Then, both aspects of design thinking from two curricula were compared to see the difference. The findings indicate that the sophomore and the senior Interior Architecture students have similarly design thinking: they tend to be "Creative Analyzer" (Piyachat, 2014) and "Conservative Analyzer" (Piyachat, 2014). The design thinking of sophomore and the senior Interior Design students have considerably changed from diverging thinking to converging thinking that is called "Conservative Analyzer" (Piyachat, 2014) and "Conservative Acceptor" (Piyachat, 2014).The pattern of design thinking and learning style from these two curricula are different. The findings indicate that the curricula can be improved the thinking and learning styles of design students in Thailand and can be used to develop teaching and learning style for Interior Architecture and Design curricula. However, design thinking should be improved with other factors such as "Physical Environment" which the future study should be continuously explored
\end{abstract}

Keywords: Interior Education; Design Thinking; Diverging Thinking; ELT model

eISSN: 2398-4287O 2017. The Authors. Published for AMER ABRA by e-International Publishing House, Ltd., UK. This is an open access article under the CC BYNC-ND license (http://creativecommons.org/licenses/by-nc-nd/4.0). Peer-review under responsibility of AMER (Association of Malaysian Environment-Behaviour Researchers), ABRA (Association of Behavioural Researchers on Asians) and cE-Bs (Centre for Environment-Behaviour Studies), Faculty of Architecture, Planning \& Surveying, Universiti Teknologi MARA, Malaysia.

https://doi.org/10.21834/e-bpj.v2i6.980

\subsection{Introduction}

The most challenge of education in the twentieth-first century is how students developed their thinking skills. From this stage, educators in design's fields have started to explore the characteristics of thinking and learning styles of students that can be used for enhancement of learning in design (Dmirbas, 2001; Demirbas and Demirkan, 2003; Kvan and Yunyan, 2005; Uluoglu, 2000). Although the current research in design disciplines has expanded and substantiated Kolb' s Experiential Learning Theory (ELT) model, few are known for learning style and design thinking of students in design disciplines in

eISSN: 2398-42870 2017. The Authors. Published for AMER ABRA by e-International Publishing House, Ltd., UK. This is an open-access article under the CC BYNC-ND license (http://creativecommons.orglicenses/by-nc-nd/4.0). Peer-review under responsibility of AMER (Association of Malaysian EnvironmentBehaviour Researchers), ABRA (Association of Behavioural Researchers on Asians) and cE-Bs (Centre for Environment-Behaviour Studies), Faculty of Architecture, Planning \& Surveying, Universiti Teknologi MARA, Malaysia. https://doi.org/10.21834/e-bpj.v2i6.980 
Thailand. As education can improve quality of life, it is more important to investigate this issue. Therefore, this research aims to explore the aspects of design thinking of students from two different curricula: Interior Architecture (five years curriculum) and Interior Design (four years curriculum) in Thailand to see what aspects of design thinking of students are different and how the curriculum can improve their design thinking.

\subsection{Literature Review}

\subsection{Experiential Learning Theory (ELT)}

Kolb's Experiential Learning Theory (ELT) presents four states of learning that seeks to integrate cognitive and socioemotional factors and to identify the pattern of thinking and learning. The first state, called "Concrete Experience (CE)," defines as the learners who involve themselves fully openly and without bias in new experiences. The second state is "Reflective Observation (RO)," the learners who observe and reflect on these experiences from many perspectives. "Abstract Conceptualization ( $\mathrm{AC}$ )" is the third state, and it defines as the learners who create concepts that integrate their observations into logically sound theories. The last state is called "Active Experimentation (AE)," the learners use these theories to make decisions and solve problems (Kolb, 1984). From these four stages, Kolb developed four learning and thinking styles a brief self-descriptive inventory called the Learning Style Inventory (LSI) to measure differences in learning styles along the two basic dimensions of abstract-concrete and active-reflective (Kolb, 1976). We have called these four styles: accommodating, diverging, assimilating thinking and converging thinking (Candy Carmel-Gilfilen, 2012).

Accommodating learners are best at felling and doing ( $\mathrm{CE}$ and $\mathrm{AE}$ ). They are relying on intuition to complete tasks rather than analytical abilities, seek out the new experience, often rely on others for information and prefer to work in teams and test multiple solutions. They tend to be "risk-taking," and this characteristic is an expecting outcome of design students (Natasha and Jason, 2015).

Diverging learners are best at the feeling and watching (CE and RO). They are sensitive and emotional and often approach a task from many different perspectives, prefer to watch, gather information and use imagination to solve problems. They prefer to work in teams for listening carefully to all suggestion before deciding on a solution.

Assimilating learners are best at thinking and watch ( $\mathrm{RO}$ and $\mathrm{AC}$ ). They are practical and approach a task using logic, interested in an idea, abstract concepts, sound theories and able to put information into a logical form, prefer to work independently and show the preference for lectures and reading.

Converging learners are best at thinking and doing ( $\mathrm{AC}$ and $\mathrm{AE}$ ). They are logical and unemotional, show the preference for technical tasks and problems and determine solutions to problems based on their strong analytical abilities rather than rely on people. This LSI model as shown in Figure1. (Candy Carmel-Gilfilen, 2012)

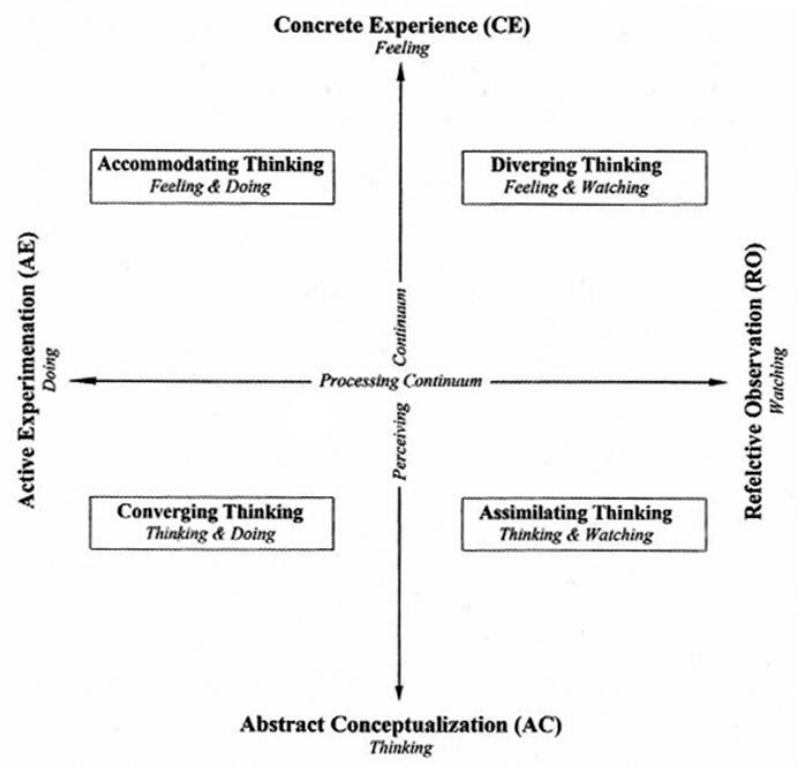

Fig.1 ELT learning model. 


\subsection{Learning style and design thinking in interior design discipline}

Kolb's ELT and LSI has been used in over two thousand research studies across professional fields (Candy Carmel-Gilfilen, 2012), including the disciplines of interior design and interior architecture. The research found that the majority of interior design students in the United States were diverging and accommodating learners (Bender, 2004; Nussbaumer and Guerin, 2000). These studies support the notion that interior designers show the preference for $\mathrm{CE}$. While conversely research by Demirbas and Demirkan (2003, 2007); Kvan and Yunyan (2005); Natasha and Jason, (2015) found that interior architecture students in Turkey and China as converging and assimilating learners. This finding illustrated that the different curriculums influence the leaning and thinking styles of design students.

Also, Kolb (Kolb, 1976) described in the inquiry norms of academic disciplines that "the indexes reveal a pattern of relationships among academic fields that are highly consistent with the managerial learning styles data. The results suggest that the commonly accepted division of academic fields in two camps, the scientific and the artistic, or abstract and concrete, might be usefully enriched by the addition of a second dimension, namely, active-reflective or applied-basic. When academic fields are mapped in this two-dimensional space, a fourfold typology of disciplines emerges. In the abstract-reflective quadrant are clustered the natural sciences and mathematics, while the abstract-active quadrant includes the science-based professions, most notably the engineering fields. The concrete-active quadrant encompasses what might be called the social profession, such as education, social work and law. The concrete-reflective quadrant includes the humanities and social sciences. Further evidence for the validity of this typology can be seen in the different ways that knowledge is structured and created in these fields." The groupings of academic fields based on these indexes are shown in Figure2 (Kolb, 1981). This previous research has assumed that the design disciplines such as Architecture, Interior Architecture, and Interior Design tend to be similarly orientations of academic fields.

The term "Design Thinking" has been part of the collective consciousness of design researcher (Kees Dorst, 2011). The first Design Thinking Research Symposium was an exploration of research into design and design methodology, viewed from a design thinking perspective (Cross, Dorst and Roozenburg. 1992). Multiple models of design thinking have emerged since then, based on widely different ways of viewing design situation and using theories and models from design methodology, psychology, education, etc. Especially the design thinking focuses on the strategies for deals with the complex and open-ended challenges faced by contemporary organizations (Stacey, Griffin and Shaw, 2000). Then, understanding how design students are thinking and learning is interesting because Interior Architecture and Design students have been dealing with open, complex problem and for developing teaching and learning skills for Interior Architecture and Design curricula.

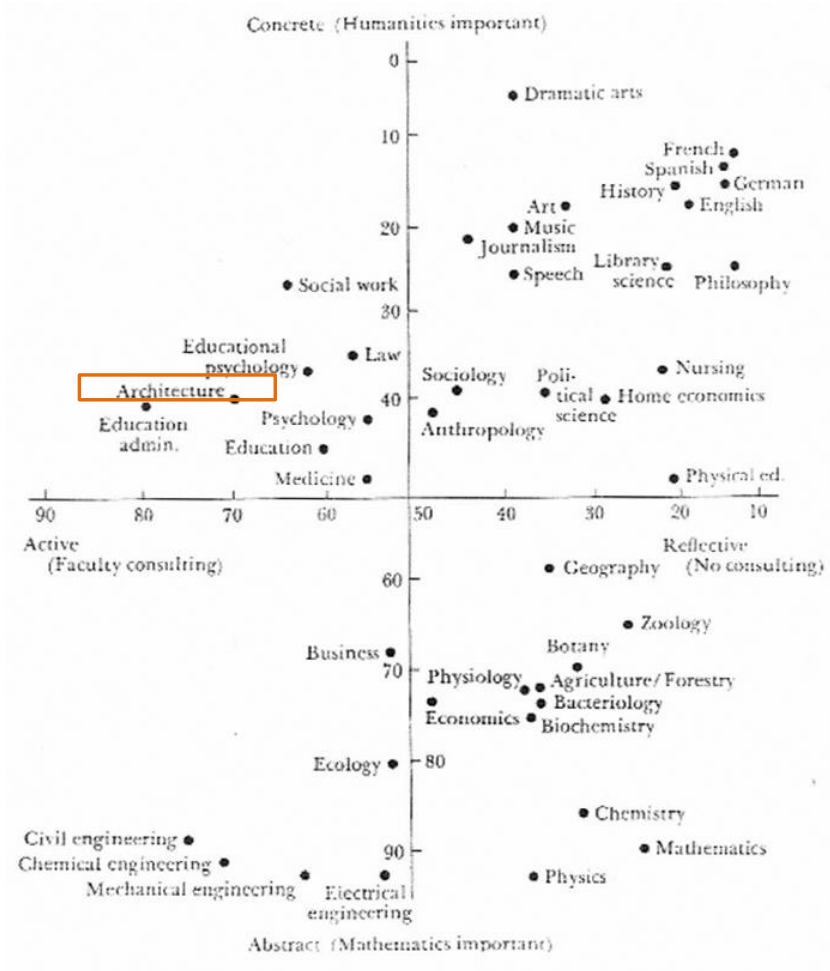

Fig 2 Concrete-Abstract and Active-reflective Orientation of Academic Fields Derived from Carnegie Commission Study 


\subsection{Interior Architecture and Interior Design Curriculums in Thailand}

In Thailand, Interior Architecture and Interior Design academics are offered by 12 institutions of higher education that accreditation by Architect Council of Thailand (Architect Council of Thailand, 2010). The research, there are two Universities which different curricula for undergraduate: Interior Architecture (five years curriculum) and Interior Design (four years curriculum). The two curriculum consisting credit hours are compared with the accreditation by Architect Council of Thailand as shown in Table1.

Table1. A curriculum consisting credit hours compare with the accreditation by Architect Council of Thailand.

\begin{tabular}{|c|c|c|}
\hline \multirow{2}{*}{ Courses } & \multicolumn{2}{|c|}{ Interior Architecture (five years curriculum) } \\
\cline { 2 - 3 } & Architect Council of Thailand credit hours & Interior Architecture \\
\hline Core Courses & $\geq 36$ & 56 \\
\hline Basic Course & $\geq 24$ & 27 \\
\hline Technology Courses & $\geq 21$ & 30 \\
\hline Support Courses & $\geq 15$ & 27 \\
\hline Elective Course & Not specification & 146 \\
\hline Total & $\geq 96 \quad$ Interior Design (four years curriculum) \\
\hline Courses & \multicolumn{2}{|c|}{ Interior design } \\
\hline & Architect Council of Thailand credit hours & 45 \\
\hline Core Courses & $\geq 33 \quad 21$ & 21 \\
\hline Basic Course & $\geq 15$ & 18 \\
\hline Technology Courses & $\geq 6$ & 21 \\
\hline Support Courses & Not specification & 6 \\
\hline Elective Course & $\geq 75$ & 111 \\
\hline Total & \multicolumn{2}{c|}{} \\
\hline
\end{tabular}

(http://act.or.th/th/accredited_degree)

According to the importance of design thinking and learning style, this research presents the following research questions:

RQ1: What are the differences between design thinking and learning styles with the sophomore and the senior students of each curriculum?

$\mathrm{RQ2}$ : What are the pattern of design thinking and learning styles from these two different curricula?

\subsection{Methodology}

This research was designed to explore the patterns of design thinking of Thai students who study in Interior Architecture and Interior Design curriculum. The research method was based on quantitative research approach, and the research design was a survey. A questionnaire was developed from Perry scheme of intellectual development, Kolb's Experiential Learning Theory (ELT) and model of Jittam (2014).

\subsection{Participants}

120 students were selected from two universities that had two different curricula for Interior Architecture (five years curriculum) and Interior Design (four years curriculum). Also, the participants were volunteers and were selected from the sophomore students ( 30 students) and the senior students ( 30 students) of each curriculum.

\subsection{Procedure}

Data for this research were gathered in the first semester of 2016. The researcher informed the aim of this research to students. Then, they were asked to fulfill the questionnaire that contains 12 questions from Kolb's Experiential Learning Theory (ELT) model (Langrehr, J: 2005 and Prof. Piyachart Jittam: 2014). However, they did not know about the style of design thinking from these questions. In the end, the participants returned their questionnaires to the researcher.

\subsection{Questionnaire}

The questionnaire consists of two parts. The first part asked basic information relating to characteristics of participants. The second part consists of 12 questions. Each question aims to investigate students' learning style so that there are two answers to each question that the participants can choose as shown below.

1) While attending a group discussion, you would ... (Example from Questionnaire)
a) Think it is unnecessary to initiate discussions
b) Look forward to sharing opinions and start discussions 


\subsection{Data Analysis}

To explore the pattern of design thinking of the students, the answers to 12 questions in the questionnaire was counted. For examples, if the participant answers a) in Question Number 1, the mark was counted in the replication score in the row of Active Experimentation ( $\mathrm{AE}$ ) as shown in Table 3. Each answer was counted and put the mark in the replication score. Then, the total mark was plotted in the ELT model as shown for example in Figure3.

Table2. The replication from a questionnaire

\begin{tabular}{|c|c|}
\hline \multicolumn{2}{|c|}{ Replication } \\
\hline 1. a) Active Experimentation ( $\mathrm{AE}$ ), & 7. a) Abstract Conceptualization (AC), b) Concrete Experience (CE) \\
\hline b) Abstract Conceptualization (AC) & 8. a) Active Experimentation ( $A E$ ), b) Reflective Observation (RO) \\
\hline 3. a) Abstract Conceptualization (AC), b) Concrete Experience (CE) & 9. a) Abstract Conceptualization (AC), b) Concrete Experience (CE) \\
\hline 4. a) Active Experimentation (AE), & 10. a) Active Experimentation (AE), \\
\hline 5. a) Active Experimentation ( $\mathrm{AE}$ ), & b) Abstract Conceptualization (AC) \\
\hline 6. a) Abstract Conceptualization (AC), b) Abstract Conceptualization (AC) & 12. a) Reflective Observation (RO), \\
\hline
\end{tabular}

Table3. The replication scores

\begin{tabular}{|c|c|}
\hline Four states of learning & Score \\
\hline Active Experimentation (AE) & 1 \\
\hline Reflective Observation (RO) & \\
\hline Abstract Conceptualization (AC) & \\
\hline Abstract Conceptualization (AC) & \\
\hline
\end{tabular}

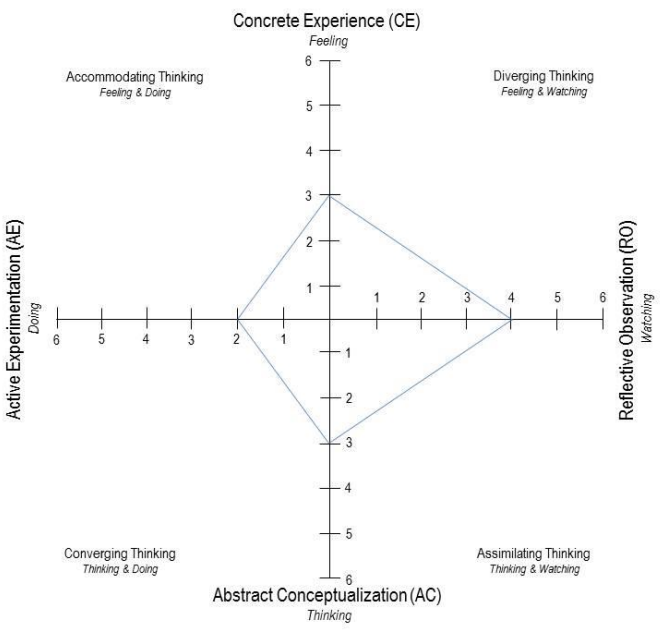

\begin{tabular}{|c|c|}
\hline Four state of learning & Score \\
\hline Active Experimentation (AE) & 2 \\
\hline Reflective Observation (RO) & 4 \\
\hline Abstract Conceptualization (AC) & 3 \\
\hline Abstract Conceptualization (AC) & 3 \\
\hline
\end{tabular}

Fig. 3 The patterns of design thinking from plotted score

\subsection{Findings}

$\mathrm{RQ1}$ : What are the differences between design thinking and learning styles with the sophomore and the senior students of each curriculum?

Interior Architecture, five years curriculum): Each pattern of the sophomore students ( $\mathrm{n}=30$ ) thinking and learning style was plot as shown in Figure 4a, and the boundary of similarly patterns consist of the aspects of design thinking of the students as shown in Figure 4b. 


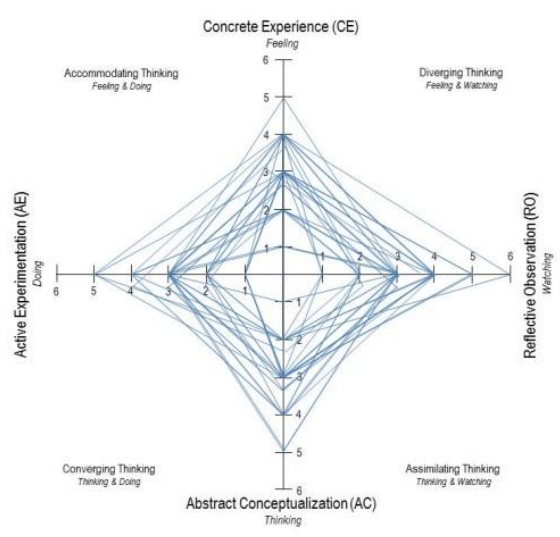

(a)

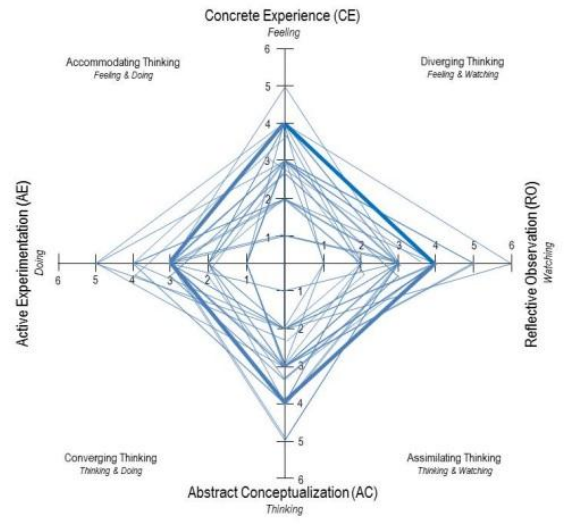

(b)

Fig.4 (a) patterns of the sophomore students thinking and learning style, (b) the boundary of similar patterns of design thinking of the sophomore students

From this stage, the sophomore students tend to be "Diverging Thinking" or "Creative Analyzer" (Piyachat, 2014) and "Assimilating Thinking" or "Conservative Analyzer" (Piyachat, 2014). In the same way, each pattern of the senior students $(n=30$ ) thinking and learning styles was plotted, and the aspects of design thinking of the students are shown in Figure 5.

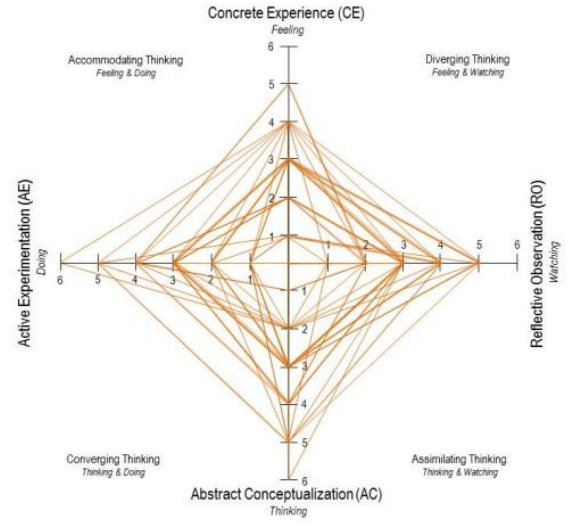

(a)

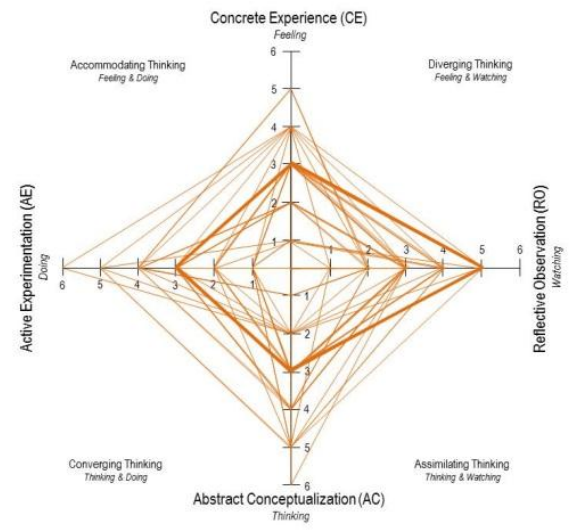

(b)

Fig.5 (a) patterns of the senior students thinking and learning style,

(b) the boundary of similar patterns of design thinking of the senior students

As the sophomore students, the senior students tend to be "Diverging Thinking" and "Assimilating Thinking." While the vertical direction (perception continuum) decreases, the horizontal direction (processing continuum) as shown in Figure 1 (Candy Carmel-Gilfien, 2012.) increases and moves forward to RO. The comparison of the patterns of thinking and learning styles are shown in Figure 6.

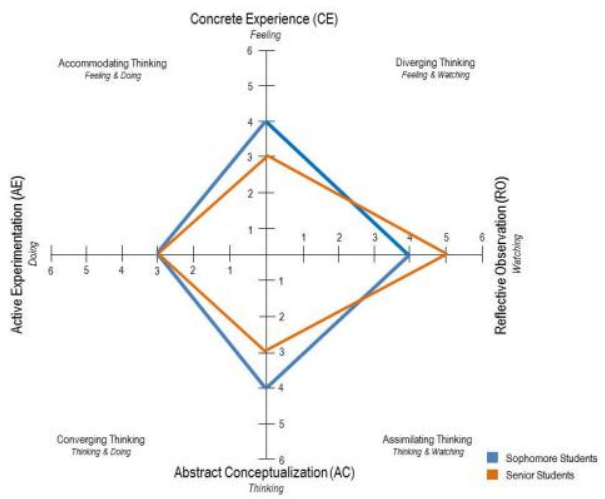

Fig.6 The patterns of Interior Architecture students thinking and learning styles 
Interior Design, (four years curriculum): patterns of the sophomore students $(\mathrm{n}=30$ ) thinking and learning styles and the boundary of similarly patterns consist of the aspects of design thinking of the students as shown in Figure7.

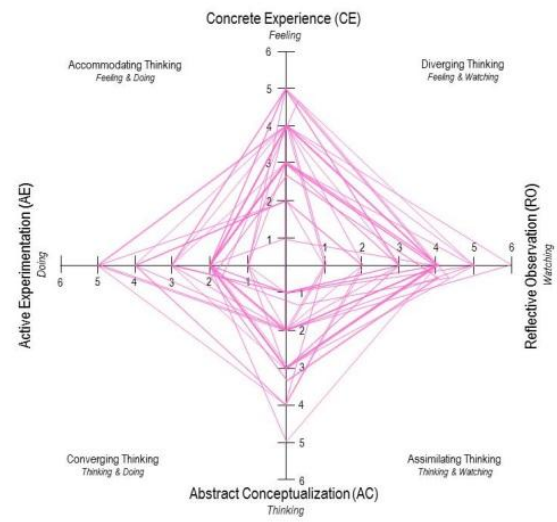

(a)

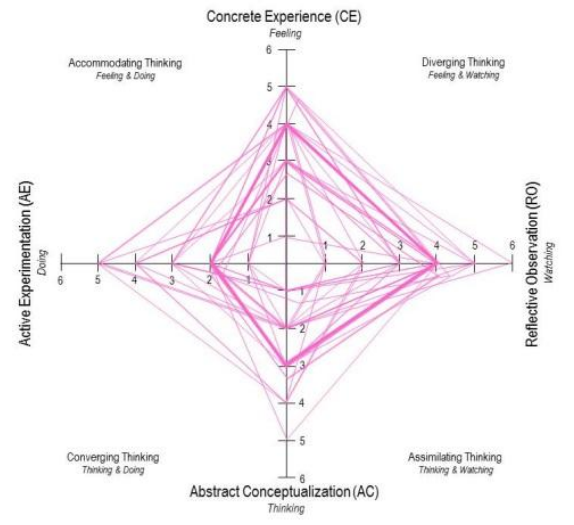

(b)

Fig.7 (a) patterns of the sophomore students thinking and learning style, (b) the boundary of similar patterns of design thinking of the sophomore students

From this stage, the patterns of the sophomore students were combined in the vertical direction (perception continuum) (Candy Carmel-Gilfien, 2012.). The students tend to be "Diverging Thinking." In addition, each pattern of the senior students $(n=30)$ thinking and learning styles was plotted, and the aspects of design thinking of the students are shown in Figure8.

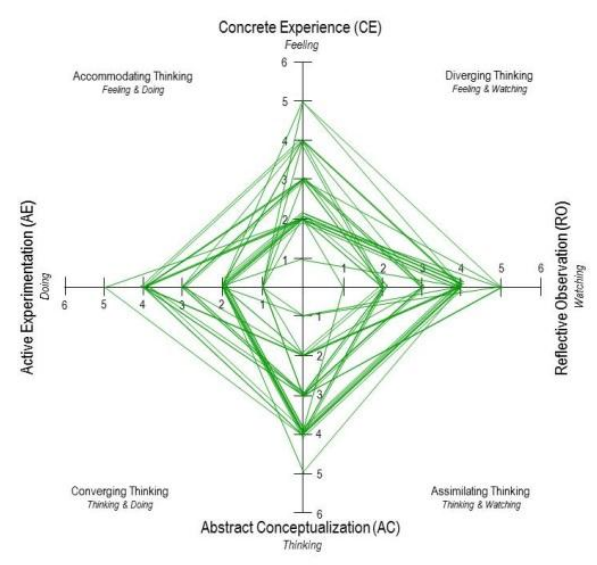

(a)

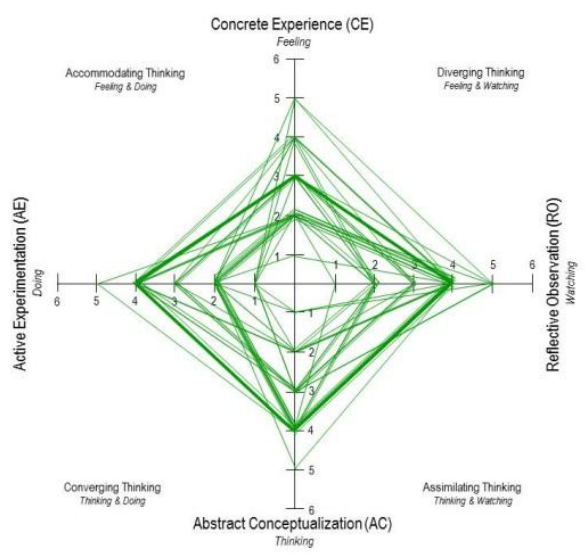

(b)

Fig.8. (a) patterns of the senior students thinking and learning style, (b) the boundary of similar patterns of design thinking of the senior students

These aspects, the senior students highly different with the sophomore students. While the vertical direction (perception continuum) decreases, the horizontal direction (processing continuum) (Candy Carmel-Gilfien, 2012.) increases and moves 
forward to $\mathrm{AC}$ and $\mathrm{AE}$. On the other hand, the senior students tend to be approaching a task by thinking and watching (Assimilating Thinking) or "Conservative Analyzer"(Piyachat, 2014) and thinking and doing (Converging Thinking) or "Conservative Acceptor" (Piyachat, 2014). The comparison between the patterns of thinking and learning styles between the senior students and the sophomore students are shown in Figure 9.

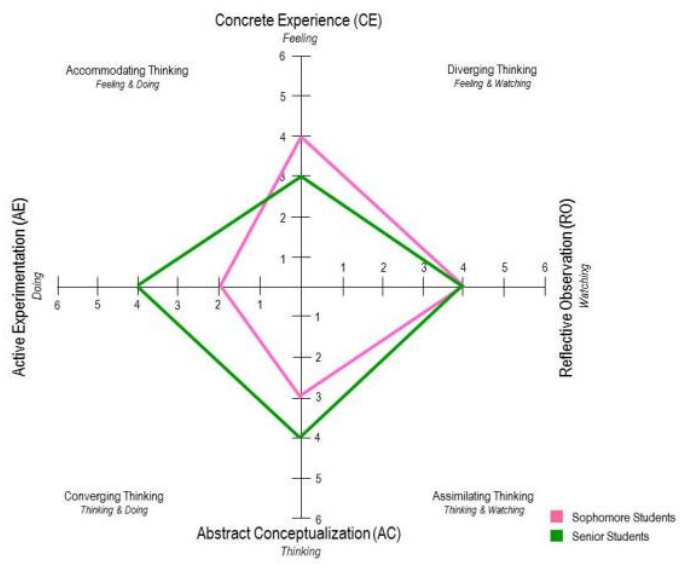

Fig.9 The patterns of Interior Design students thinking and learning styles.

\section{RQ2: What are the pattern of design thinking and learning styles from these two different curricula?}

The patterns show that the thinking and learning styles of the students from these two different curricula have been changed in the different direction. Especially the thinking and learning styles of interior design curriculum from perception continuum approach ( $C E$ and $A C$ ) to the processing continuum approach ( $R O$ and $A E$ ) as shown in Figure10.

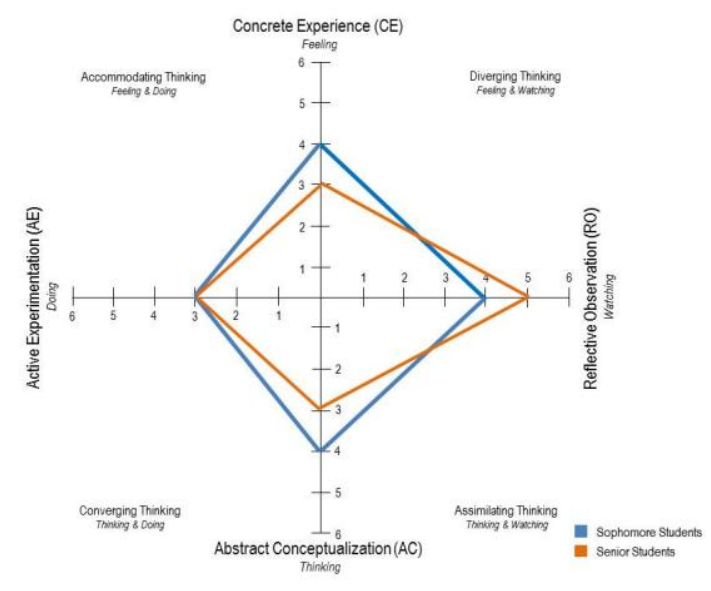

(a)

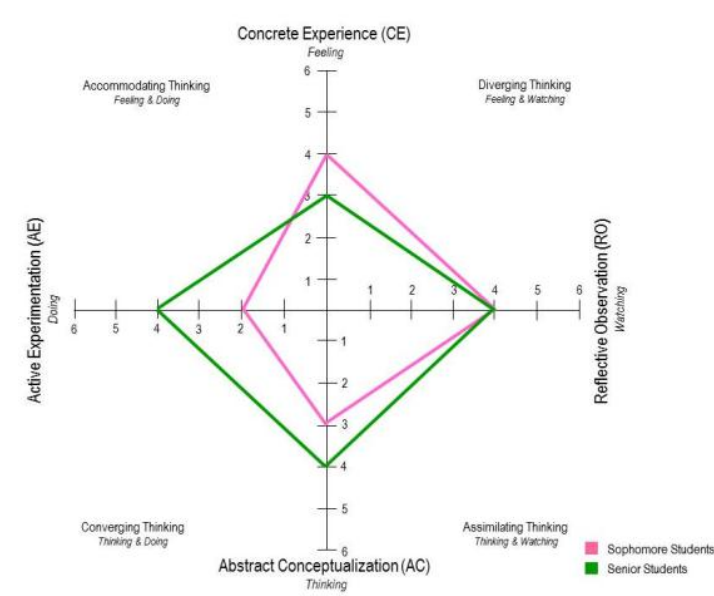

(b)

Fig.10 (a) patterns of the Interior Architecture thinking and learning style, (b) patterns of the Interior Design thinking and learning style

\section{Discussion and Conclusion}

Kolb's ELT and LSI provides an appropriate context for exploring the thinking and learning styles of design students. In this research with compared the thinking and learning styles from sophomore and senior students in Thailand have developed moderately in Interior Architecture curriculum and considerably in Interior Design. The comparison of the thinking style from this finding with the previous research are shown in Table 4.

Table4. Compared the thinking style from the finding with the previous research

\begin{tabular}{|l|c|c|}
\hline \multicolumn{1}{|c|}{ Curriculums } & The previous research & The findings \\
\hline Interior Architecture (five years) & Converging thinking and Assimilating thinking & Diverging Thinking and Assimilating Thinking \\
\hline Interior Design (four years) & Diverging thinking and Accommodating thinking & Converging thinking and Assimilating thinking \\
\hline
\end{tabular}


These stages indicated that the curricula influence the thinking and learning styles of design students. Although the expecting outcome of design students: accommodating thinking (CE and AE) or "risk-taking" (Natasha and Jason, 2015) are not shown in these aspects, understanding the situation will arouse the educators in Thailand to improve a curriculum for all design students to develop their design thinking and learning style.

While this research aims to explore the aspects of design thinking of students from two different curricula. However, design thinking should be improved with another factor such as "Physical Environment" (Supaporn,2003) (Moore, 2007) which the future study should be continuously explored.

\section{Acknowledgements}

The author would like to thank Assistant Professor Chumporn Moorapun for his valuable guidance and the author would also like to thank all participants for important data.

\section{References}

Alice Y. Kolb, (2005). The Kolb Learning Style Inventory-Version 3.12005 Technical Speciation. Experience Based Learning Systems, Inc. Case Western Reserve University.

Candy Carmel-Gilfien, (2012). Uncovering Pathways of Design Thinking and Learning: Inquiry on Intellectual Development and Learning Style Preference. Journal of interior design, 37,3), 47-66

David A. Kolb, (1981). Learning Style and Disciplinary Difference. Jossey-Bass Inc. San Francisco, California, United States

Erin Cunningham, (2014). Navigating the Past: What does History Offer the Discipline of Interior Design.Journal of interior design, 3933, 5-12.

Halime Demirkan and O.Osman Demirbas, (2008). Focus on the learning styles of freshman design students. Design Study, 29,2008), 254-266.

Hasan Bacanli, Mehmet Ali Dombayci, Metin Demir, Sinem Tarhan I, (2011). Procedia - Social and Behavioral Sciences, 12 (2012), $536-544$

Kees Dorest, (2011). The core of "design thing" and its application. Design Study, 32(2011), 521-532.

Natsha Ellis, (2015). Springboards and Barriers to Creative Risk-Taking and Resolve in Undergraduate Interior Design Studios. Journal of interior design, $40,4), 17-40$

O.Osman Demirbas, Halime Demirkan, (2007). Learning styles of design students and the relationship of academic performance and gender in design education. Learning and Instruction 17,2007, 345-359. 